\title{
The Diagnostic Value of C-Reactive Protein and total Leukocytes Count in Patients with acute Abdominal Pain in Children.
}

\author{
Ferizat Dika - Haxhirexha ${ }^{1}$, Agron Dogjani ${ }^{2}$, Ledia Kaçi ${ }^{3}$, Lutfi Zylbehari ${ }^{3}$, Kastriot Haxhirexha ${ }^{3}$.
}

Received: 09 April 2018; Accepted: 30 June 2018; Published online: 20 July 2018

DOI: https://doi.org/10.32391/ajtes.v2i2.9

\section{Abstract}

Background: C-reactive protein (CRP) is one of the acute-phase proteins which increases during inflammatory conditions. Nowadays, C-reactive protein (CRP) is a commonly used biomarker especially in emergency department (ED) for diagnostics of febrile and infectious patients. It is almost impossible to distinguish the bacterial from nonbacterial (viral) infection by CRP level only - so the detailed history of onset of disease is very important to establish the diagnosis of bacterial infection as a cause of acute abdominal pain.

Objective: The aim of this study was to establish the diagnostic value of leucocyte and CRP count in in diagnosing acute abdominal pain.

Material and methods: We retrospectively evaluated 159 patients with acute abdominal pain admitted to the surgical department of the Clinical Hospital of Tetova and PHO "Alba - Med" over a period of 2 years respectively from January 20016 to January 2018. All patients included in this study was aged between five to 15 years old.

Results: During the study period there were 158 patients ( 96 were females and 56 males). All the patients suffered from acute abdominal pain, whereas 45 of them had a surgical condition, respectively in 42 of them acute appendicitis as a cause of pain, Meckel's diverticulitis, jejunal intussusception and ruptured ovarian cyst in three other patients. In 105 patients nonsurgical condition was the reason of acute abdominal pain. CRP was performed within $24 \mathrm{~h}$ after admission in all the patients. In the group of patients with surgical disease in 41 of them (91\%) the value of CRP was more than $>5 \mathrm{~g} / \mathrm{L}$.

Conclusions: According to our experience we conclude that the CRP level is not sufficient to predict patients with acute abdominal pain that require surgical treatment.

Key words: CRP, acute abdominal pain, surgery

*Corresponding author; Kastriot Haxhirexha MD, PhD, Medical Faculty - Tetova, Macedonia

$\equiv$ Email: dr.kastriot@gmail.com

1Pho "Alba Med"

${ }^{2}$ University Hospital of Trauma Tirana, Albania

${ }^{3}$ Clinical Hospital - Tetova, Medical Faculty - Tetova, Macedonia 


\section{Introduction}

C-reactive protein (CRP) represents one of the acute-phase proteins (APPs), which serum level changes rapidly in the presence of inflammatory conditions, by at least $25 \%$, ${ }^{6}$. C reactive protein (CRP) was discovered in 1930 whereas this name received because reacts with the $\mathrm{C}$-polysaccharide of the pneumococcus bacteria in the acute phase of pneumococcal pneumonia ${ }^{1,4}$. CRP can be useful to screen many inflammatory conditions but without the possibility to distinguish accurately the etiology of the inflammation process because increased values of CRP are registered not only in infectious diseases, but also in the presence of systemic inflammation caused by rheumatoid arthritis, myocardial infarction, necrotising soft tissue infections, multiple trauma, neoplastic processes, pancreatitis etc., This is why it is not recommend to use CRP to differentiate inflammatory conditions from infectious diseases ${ }^{2.3}$.

CRP is predominantly synthesized by the liver and its level in the blood starts to rise four to six hours after the inflammation and it duplicates every eight hours, while the maximum value is registered within 36 to 50 hours.

The plasma half-life of CRP is about 19 hours whereas it may take several days to return to the baseline level ${ }^{20}$

Due to its long half-life in the serum, CRP may remain high during recovery phase, but if reduction of CRP is not registered 72 hours after treatment a re-evaluation of the course of the disease is recommended ${ }^{16,17}$.

Leucocyte count still remains the most frequently used laboratory test in diagnosing acute abdominal pain. The range of sensitivity and specificity of WBC for the diagnosis of acute abdomen in several clinical studies have been reported to be between
$67 \%$ and $97.8 \%{ }^{7}$, whereas in this context neutrophil count has been detected as a superior diagnostic marker for differential diagnosis of acute abdomen. In most studies it is estimated that a neutrophil ratio above $85 \%$ is a safe sign of advanced acute appendicitis ${ }^{9,11}$.

The aim of this study was to evaluate the diagnostic value of leucocyte and CRP count in in diagnosing acute abdominal pain.

\section{Materials and methods}

All patients admitted in our clinic with a clinical sign of acute abdominal pain between January 2015 - 2018 were studied retrospectively. After admission the diagnosis of patients with acute abdominal pain was established by medical history, physical examination, CRP level, white blood cell (WBC) count and sometimes imaging tests such as plain abdominal radiography, ultrasonography and abdominal CT scan.

According to the results of physical examination, laboratory results as well as ultrasonography and abdominal computed tomography examination, patients were divided into two groups.

The first group included the patients with nonsurgical conditions, whereas the second group all the patients with surgical diseases (in total 45 patients).

\section{Results}

During the study period there were 159 patients (72 of them were males and 87 females) (Diagram 1). 

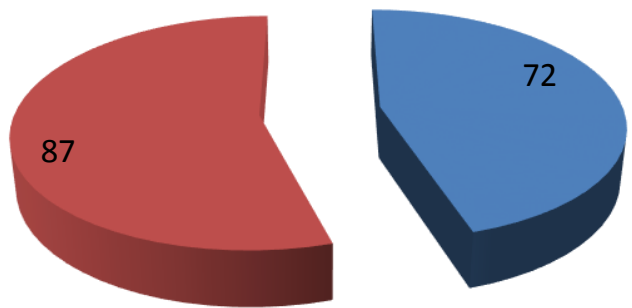

Males Females

Graph 1

The mean age of children included in this study was 10.01 years, ranging from five to fifteen years (Diagram 2).

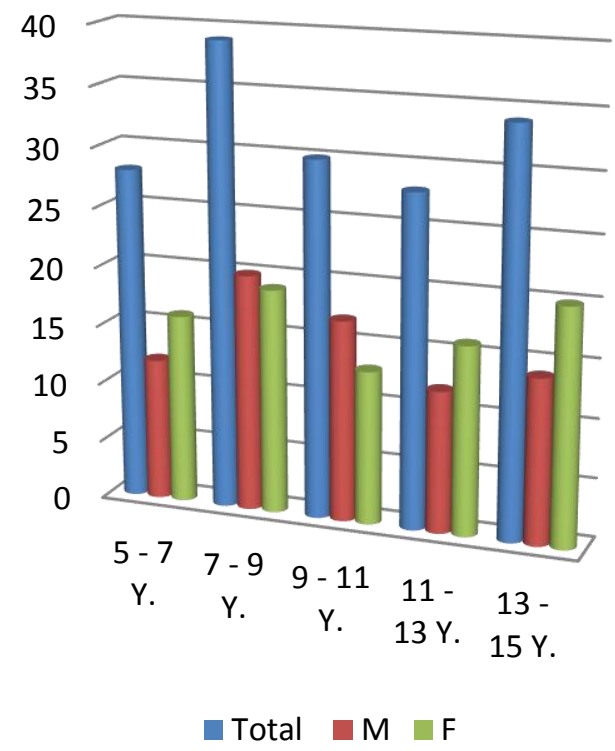

Graph 2

All the patients included in this study complained for acute abdominal pain. After careful examination and clinical evaluation it was noticed that in 47 patients a surgical condition was the cause of acute abdominal pain, whereas in 108 children a non- surgical disease was the reason of complaint. Anamnestic data revealed that in children with surgical conditions the pain usually begins in the periumbilical region and then was localized in the RLQ region, whereas during examination all the patients had a rebound tenderness in the right iliac fossa. In the group of patients with non-surgical disease pain started mainly in the epigastrium or around umbilicus and then scattered across the abdominal cavity.

The most common cause of acute pain in the group of children with surgical disease was been acute appendicitis - in 42 of them, whereas Meckel's diverticulitis, jejunal intussusception and ruptured ovarian cyst was a cause of acute abdominal pain in the remaining three patients.

\section{Surgical cause}

Acute appendicitis

Meckel's diverticulitis

- Jejunal intususception

Ruptured ovarian cyst

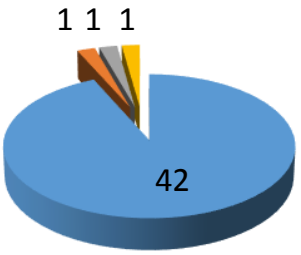

\section{Graph 3}

In the group of children with non-surgical abdominal pain, mesenteric lymphadenitis, dyspepsia, acute gastroenteritis and pelvic inflammatory disease was the most common cause of pain.

In all the patients after admission blood samples were obtained and CRP level and WBC were determined. In the group of patients with surgical disease the level of CRP more than $5 \mathrm{~g} / \mathrm{L}$ was 
registered in 33 patients or $73 \%$, whereas in a group with non-surgical conditions the level of CRP $>5 \mathrm{~g} / \mathrm{L}$ was registered in 75 children or $65 \%$. Repeated measurements of CRP were performed in all patients with surgical condition and in 33 of them CRP was steadily high, whereas in twelve others was registered a decrease in CRP level.

WBC count was also performed in all patients and moderate leukocytosis $\leq 15.000 / \mathrm{mm} 3$ was registered in 39 patients ( $86 \%$ ) with surgical conditions and in 81 children (70\%) with nonsurgical diseases.

Abdominal plain radiography was performed in 59 patients included in our study, 18 of which was been with surgical diseases whereas 41 with nonsurgical conditions. Our assessment was that plain radiography does not show a high sensitivity or specificity for the diagnosis of acute appendicitis and should not be ordered in this group of patients, but my be of particular importance in differential diagnosis of the acute abdominal pain.

Abdominal CT has been shown to have a greater sensitivity and accuracy not only for the diagnosis of acute appendicitis but also for the diagnosis of other causes of acute abdominal pain. We have performed totally 39 abdominal CT in patients of this study, 11 of which were from the first group and 28 from the second.

According to our experience it seems that ultrasound examination has a great sensitivity and accuracy rate for acute appendicitis and intussusception.

\section{Discusion}

Despite the recent advances in the diagnostic modalities the diagnosis of acute abdomen still remains a challenge in pediatric practice. For this reason, different diagnostic techniques such as abdominal ultrasound, CT scanning, and laboratory examinations have been used to improve the diagnostic accuracy.

Recently one of the most used biomarker in the emergency department to facilitate the diagnosis of acute abdomen is the C-reactive protein (CRP) ${ }^{6,8,12}$. Prospective studies showed that this marker may be useful not only in establishing the diagnosis of acute appendicitis, but also plays a diagnostic role in acute abdominal pain ${ }^{16,17,18,19}$. Another parameter that helps to determine the etiology of acute abdominal pain is also white blood cell count $(\mathrm{WBC})^{24,5}$. It is estimated that C-reactive protein and WBC count can be helpful in the diagnosis of acute abdomen ${ }^{9,10,11}$.

In many studies conducted over the last years it is estimated the diagnostic value of CRP in acute abdominal pain and most of them have concluded that CRP alone is not useful in differentiating between surgical and non-surgical causes of acute abdomen ${ }^{13,14,15}$. Other studies emphasize the role of white cell count and C-reactive proteins in the diagnosis of acute appendicitis and they report a high sensitivity and specificity of these parameters in the diagnosis of acute abdominal pain ${ }^{21,22}$. Our study shows that the specificity of CRP to diagnose the cause of acute abdominal pain was very low, but combination of WBC count and Creactive proteins give a more valuable information for the diagnosis of acute appendicitis during acute abdominal pain ${ }^{5,7}$. It is estimated that patients with high value of CRP and WBC are highly suspected to have acute appendicitis and should be followed carefully until the decision on surgical intervention is undertaken.

Many authors as Anderson et al. ${ }^{13}$ studied the value of CRP and WBC count in patients suspected for 
acute appendicitis and found that a normal value of this parameters should be a good indication to postpone the operation.

Other authors like Chi et al. $\underline{\underline{12}}$ studied the role of CRP in patients with acute abdominal pain and concluded that CRP was helpful in decision making in patients with an acute abdomen.

Ultrasonography and computed tomography (CT) helps in setting up a diagnosis in patients with abdominal pain, considering that $\mathrm{CT}$ is likely more accurate than ultrasonography ${ }^{26}$. However according to the experience of many clinicians of the emergency department, ultrasonography is most useful in diagnosing of some group of the diseases such as PID, renal colic, advanced periappendicular inflammation etc ${ }^{29}$. Concerning $\mathrm{CT}$ it is recommended if excessive bowel gas precludes ultrasonography examination, or in the case of diseases of small and large intestine ${ }^{28,30}$. Conclusion: Increased level of CRP concentration is not sufficient to differentiate between surgical and non-surgical diseases in patients with acute abdominal pain, while the combination of CRP and WBC count provides safer data about the etiology of acute abdominal pain. However, CRP level and WBC count should be used only in adjunctions with clinical data and if possible with ECHO examination or abdominal CT-scan.

\section{References}

1. Mitaka C. Clinical laboratory differentiation of infectious versus non-infectious systemic inflammatory response syndrome. Clin Chim Acta. 2005; 351:1729.

2. Schwartz KL, Gilad E, Sigalet D, Yu W, Wong AL (2011) Neonatal acute appendicitis: a proposed algorithm for timely diagnosis. J Pediatr Surg 46: 2060-2064.
3. Guthery SL, Hutchings C, Dean JM et al (2004). National estimates of hospital utilization by children with gastr ointestinal disorders: analysis of the 1997 kids' inpatient database. J Pediatr. 144(5):589594.

4. Ilves I, Fagerström A, Herzig KH, Juvonen $P$, Miettinen P, et al. (2014) Seasonal variations of acute appendicitis and nonspecific abdominal pain in Finland. World J Gastroen- terol 20: 4037-4042.

5. Sengupta A, Bax G, Paterson-Brown S. White cell count and $C$-reactive protein measurement in patients with possible appendicitis. Ann R Coll Surg Engl 2009; 91 (2): 113-115

6. Zimmerman MA, Selzman $\mathrm{CH}$, Cothren $\mathrm{C}$, Sorensen AC, Raeburn CD, Harken AH. Diagnostic implications of $\mathrm{C}$-reactive protein. Arch Surg 2003;138 (2): 220-224.

7. Briton J. Acute abdomen. In: Morris PJ, Wood WC, editors. Oxford Textbook of Surgery. Oxford: OUP; 2000

8. Mandeville K, Monuteaux M, Pottker T, Bulloch B (2015) Ef- fects of Timing to Diagnosis and Appendectomy in Pediatric Appendicitis. Pediatr Emerg Care 31: 753758.

9. Minneci PC, Mahida JB, Lodwick DL, Sulkowski JP, Nacion KM, Cooper JN, et al. Effectiveness of Patient Choice in Nonoperative vs Surgical Management of Pediatric Uncomplicated Acute Appendicitis. JAMA Surg. 2016; 151: 40815.

10. Yazici M, Ozkisacik S, Oztan MO, Gursoy H. Neutrophil/lymphocyte ratio in the diagnosis of childhood appendicitis. Turk J Pediatr. 2010; 52: 400-3. 
11. Andersson REB. Meta-analysis of the clinical and laboratory diagnosis of appendicitis. Br J Surg. 2004; 91: 28-37

12. Chi CH, Shiesh SC, Chen KW, Wu MH, Lin $X Z$. C-reactive protein for the evaluation of acute abdominal pain. Am J Emerg Med. 1996; 14: 254-6.

13. Andersson RE, Hugander $A$, Ravn $H$, Offenbartl K, Ghazi SH, Nyström PO, et al. Repeated clinical and laboratory examinations in patients with an equivocal diagnosis of appendicitis. World J Surg. 2000; 24: 479-85

14. Colvin JM, Bachur R, Kharbanda A. The presentation of appendicitis in preadolescent children. Pediatr Emerg Care 2007; 23: 849-55.

15. Bundy DG, Byerley JS, Liles EA, Perrin EM, Katznelson J, Rice HE. Does this child have appendicitis? JAMA. 2007; 298: 438-51.

16. Wu HP, Lin CY, Chang CF, Changc YJ, Huang $\mathrm{CY}$. Predictive value of $\mathrm{C}$-reactive protein at different cutoff levels in acute appendicitis. Am J Emerg Med. 2005; 23: 449-53.

17. Beltran MA, Almonacid J, Vicencio A, Gutierrez J, Cruces KS, Cumsille MA. Predictive value of white blood cell count and $\mathrm{C}$-reactive protein in children with appendicitis. J Pediatr Surg 2007; 42:1 20814.

18. Bilavsky E, Yarden-Bilavsky H, Ashkenazi S, Amir J. C-reactive protein as a marker of serious bacterial infections in hospitalized febrile infants. Acta Paediatr 2009; 98 (11): 1776-1780.

19. Yu CW, Juan LI, Wu MH, Shen CJ, Wu JY, et al. (2013) Systematic review and metaanalysis of the diagnostic ac-curacy of procalcitonin, $\mathrm{C}$-reactive protein and white blood cell count for suspected acute appendicitis. Br J Surg 100: 322-329.

20. Ravishankaran $P$, Shah AM, Bhat R: Correlation of interleukin-6, serum lactate, and $\mathrm{C}$-reactive protein to inflammation, complication, and outcome during the surgical course of patients with acute abdomen. J Interferon Cytokine Res 2011, 31:685-690.

21. Salem TA, Molloy RG, O'Dwyer PJ: Prospective study on the role of $\mathrm{C}$ - reactive protein (CRP) in patients with an acute abdomen. Ann R Coll Surg Engl 2007, 89:233-237.

22. Meyer et al.: The value of $\mathbf{C}$-reactive protein and lactate in the acute abdomen in the emergency department. World Journal of Emergency Surgery 2012 7:22.

23. Hartman GE. Acute appendicitis. In: Behrman RE, Kleigman RM, Jenson HB, eds. Nelson Textbook of Pediatrics. 18th ed. Philadelphia, PA: Saunders, 2007:1628-34

24. Kwan KY, Nager AL (2010) Diagnosing pediatric appendi- citis: usefulness of laboratory markers. Am J Emerg Med 28: 1009-1015.

25. Bachur RG, Hennelly K, Callahan MJ, Chen C, Monuteaux MC. Diagnostic imaging and negative appendectomy rates in children: effects of age and gender. Pediatrics. 2012; 129: 877-84.

26. Ang A, Chong NK, Daneman A. Pediatric appendicitis in "real-time": the value of sonography in diagnosis and treatment. Pediatr Emerg Care 2001; 17:334-40.

27. Allemann $F$, Cassina $P$, Röthlin $M$, Largiader F. Ultrasound scans done by surgeons for patients with acute abdominal pain: a prospective study. Eur J Surg 1999; 165: 966-70 
28. Reich JD, Brogdon B, Ray WE, Eckert J, Gorell H. Use of CT scan in the diagnosis of pediatric acute appendicitis. Pediatr Emerg Care 2000; 16: 241-3.

29. Khalid M, Redhu N, Nazir B, Khalid S, Chana RS, et al. (2012) Diagnostic value of ultrasonography in evaluation and management of acute abdominal conditions in the paediatric age group. Afr J Paediatr Surg 9: 198-201.

30. Miglioretti $\mathrm{DL}$, Johnson $\mathrm{E}$, Williams $\mathrm{A}$, et al. The use of computed tomography in pediatrics and the associated radiation exposure and estimated cancer risk. JAMA Pediatr. 2013;167(8):700-707 